\title{
CORTICOSTEROID-INDUCED OSTEOPOROSIS AND OSTEONECROSIS: ROLE OF OXIDATIVE STRESS
}

\author{
Reham H. Alattar ${ }^{1 *}$, Abdel Alim F. Abdel Alim², Sabry M.A. Abdelmetal ${ }^{2}$, \\ Sayed A. Abdel Aziz ${ }^{2}$
}

'Zagazig University student's Hospital, Zagazig University, Egypt, ${ }^{2}$ Pharmacology Department, Faculty of Veterinary Medicine, Zagazig University, 44511, Egypt

*Corresponding author, E-mail: reham_attar2013@yahoo.com

\begin{abstract}
Glucocorticoids (GC) play a significant role in body metabolism. In the last few years, advances and highlights have been made to understand the role of oxidative stress induced by corticosteroids in the pathogenesis of osteonecrosis (ON) and osteoporosis (OP) and the door for digging in GC mechanistic has been opened by the newly detection of high-affinity receptors for glucocorticoids and calcitriol in bones. The harmful free radicals produced by corticosteroid administration are strong emitters of many regulatory cytokines such as tumor necrosis factor (TNF), nuclear factor kappa $\beta$ (NF-kB) and interleukins. For this, a great attention has been directed toward the possibility of using a novel free radical scavenger like natural antioxidant, e.g. ginseng, that can be helpful in the management of ON and OP. The use of antioxidants for the management of osteoporosis characterized by many improvements in the way of control the incidence rate of ON and OP. Many antioxidants have an anti-osteoporotic effect, with an overall redox state maintenance. Also, the lipid peroxides are alleviated and the intraosseous vascular integrity within the bone marrow are repaired. Moreover, the oxidative damage of DNA is contoured. The objective of this review is to highlight the role of oxidative stress in the pathogenesis of corticosteroid-induced osteonecrosis (ON) and osteoporosis (OP) and studying the possibility of using a novel free radical scavenger, a natural antioxidant, e.g. Ginseng, that can be helpful in the management of OP \& ON.
\end{abstract}

Key words: osteoporosis; osteonecrosis; corticosteroids; oxidative stress; ginseng

\section{Introduction}

Osteoporosis (OP) which is a widespread disease characterized by an abnormal mass, tissue, fragility and fracture risk of bones (1). Although, it is well known that impairment in the blood supply of the bone and administration of corticosteroids can lead to osteonecrosis, the actual mechanisms of steroid hormone action on bone and how glucocorticoid- induced osteoporosis (GIOP) and how the cellular composition of bone is altered is still obscure. Secondary osteoporosis and fracture may occur in patients receiving corticosteroids either in high-doses or chronic therapy, which is considered as one of the major risk factors for ON (2). The oxidative stress was found to inhibit the differentiation and mineralization of bone and consequently induces necrosis of osteoblasts (3), and increases the expression of 
cytokines in the bone and thus induces osteoporosis. The effects of free radicals on the bone can be countered by the use of a proper antioxidant in a way that can prevent osteoporosis.

The main topics which will be discussed in the review are:

1. Glucocorticoids.

2. Free radicals involved in osteoporosis and osteonecrosis and the possible role of antioxidants.

3. Involvement of oxidative stress in bone pathophysiology: Apoptosis and Caspases.

4. Steroid-induced OP- animal models.

5. Osteoporotic biomarkers.

\section{Glucocorticoids}

Owing to the potent anti-inflammatory effects of glucocorticoids, they are widely used as an essential mendicant (4). The prolonged use of these drugs may provide adverse effects not only on the metabolism of proteins, lipids and carbohydrates, but also has immunosuppressive effects.

Hyperglycemia is one of the most important effects that may play a role in the stress response and osteoporosis induced by glucocorticoids. The age-associated loss of bone mass and strength or the aging skeleton can be contributed to the inflammatory cytokines, but without clear molecular declare (5). In human subjects, GIO occurs in two phases: a rapid early phase in which bone mineral density falls, occurs $5-15 \%$ per year, probably due to excessive bone resorption. A slower phase, characterized by a more slowly decline of bone mineral density, and occur $2 \%$ per year, which mainly attributed to bone formation defect (6).

\subsection{Glucocorticoids mechanism}

The mechanism of glucocorticoids action is found to be mediated by glucocorticoid receptors (GCR), belong to the nuclear steroid hormone receptor family, expressed in bone cells (7). In spite of the recent success in the molecular biological techniques, the precise molecular mechanism of steroid hormone action has remained obscure. These receptors include cytosolic glucocorticoid receptor (cGCR) for both the classical genomic and non-genomic mechanism of glucocorticoid action and membrane-bound glucocorticoid receptor (mGCR) for the mediated non-genomic effects. While, the interactions with cellular membranes result in a non-specific, non-genomic effects caused by direct interaction with the cell membranes (8). Seven members of steroid receptors are recognized: estrogen receptor $a \& b$, estrogenrelated receptors $1 \& 2$, and the receptors for mineralocorticoids, androgens and progesterone $(9,10)$. The gene encoding the human GR (hGR) is located on chromosome 5 in loci 3132 (5q31-32) (11). Three main functional domains are included in each receptor; Nterminal domain, DNA-binding domain (DBD), and ligand-binding domain (LBD). Two distinct receptor forms for glucocorticoids in human, arise from alternative splicing of exon 9: hGR- $\alpha$ and hGR- $\beta$. While the classical signaling and modulation of gene expression are attributed to $\alpha$ - receptor form, while $\beta$ form may function only as a dominant negative inhibitor of $\alpha$-signaling (8).

The effects of glucocorticoids on bone differ according to the developmental stage i.e. from the beginning stage to the late stage, from human to animal species and moreover in a cell-type-specific manner (3). While GCs appear to be essential for the early osteoblastic stage, responsible for the differentiation of osteoblasts into bone-forming osteoblasts, act as inhibitory at the very late stages of osteoblast differentiation and osteocytes (12). In bone, local activation of the inactive cortisone into the active cortisol by $11 \beta$-hydroxysteroid dehydrogenase is a pivot point, is responsible for function of osteoblasts, differentiation, proliferation and. One of the most important factors that cause increases in the bone turnover, loss of bone mass and fracture risk is the changes in the levels of steroid hormone as occurs in the adulthood of either sex. In osteoblasts and osteoclasts, estrogen receptor $\alpha$ $(\mathrm{ER} \alpha)$ has a protective effect on bone $(14,15)$. 


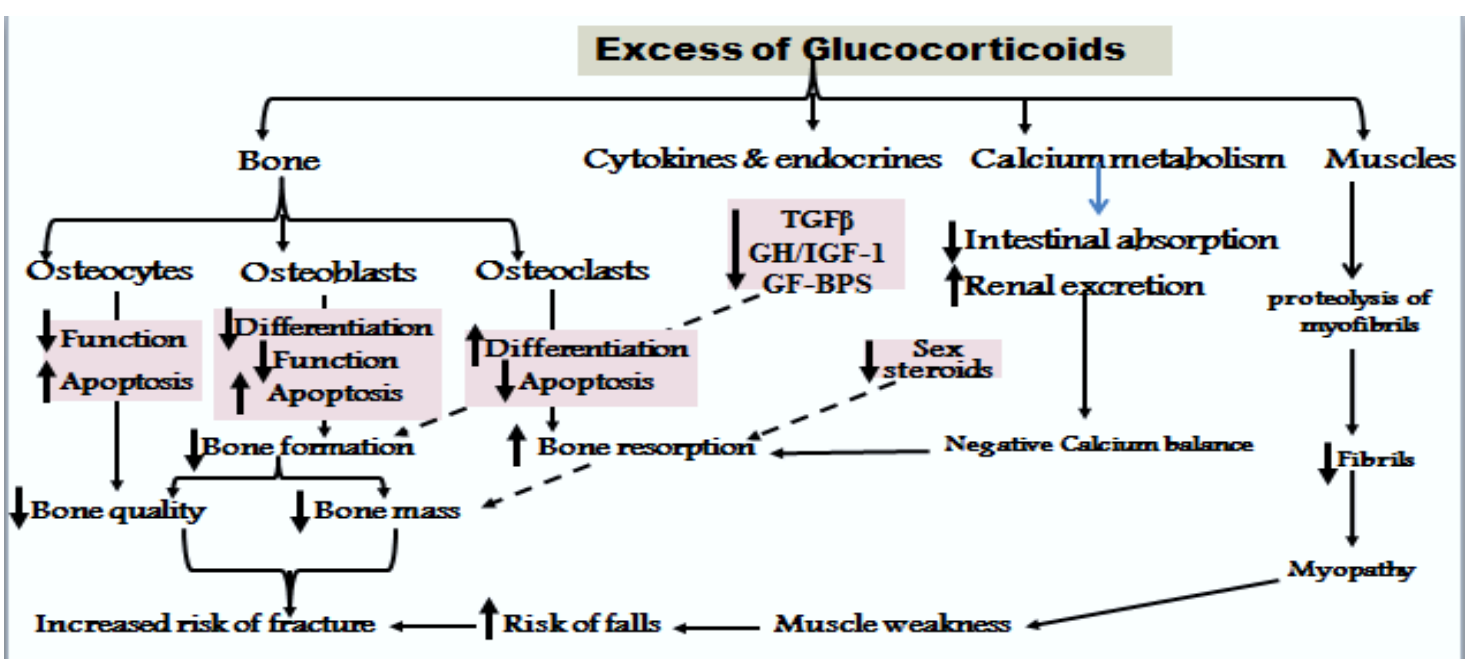

Figure 1: Pathophysiology of glucocorticoid-induced osteoporosis, adapted from $(12,13)$

\section{Free radicals involved in osteoporo- sis and osteonecrosis}

The proper bone modeling is controlled mainly by the function of two types of bone cells, osteoclasts (bone formation) and osteoblasts (bone resorption), and OP occurs when the balance between both functions is disrupted (16-18). This balance is affected by many risk factors including high-doses of corticosteroids, alcohol abuse, genetic, race, hormonal, mechanical and nutritional factors.

\subsection{Free radicals}

The presence of unpaired electron(s) in atomic or molecular orbitals makes the molecule unstable and highly reactive and considered a free radical. As shown in table (1), free radicals are usually, but not always oxygen, which include reactive oxygen species (ROS) and reactive nitrogen species (RNS) (19). Numerous agents and factors can induce significant generation of ROS, including drugs as anticancer, diseases as diabetes and environmental as UV irradiation, pollutants and toxicity (12).

As mitochondria is the major generator of ROS. In cells, the main source of $\mathrm{O}_{2}{ }^{-}$is the leakage of electron(s) from the mitochondrial ETC, and therefore the damage occurs mainly for mtDNA leading to apoptosis (20). Under physiological conditions, $\mathrm{H}_{2} \mathrm{O}_{2}$, but not $\mathrm{O}_{2}{ }^{-*}$ is produced by the peroxisomes (21). Oxygen free radicals can also be produced by NADPH oxidase on osteoclasts, and xanthine oxidase and $\operatorname{NOS}(22,23)$. Also, treatment with interferon (IFN)- $\gamma$, which act as a stimulator of the activity of NADPH-oxidase enzyme lead to liberation of free radicals.

\subsection{Hyperglycemia-induced oxidative stress}

Various mechanisms were adopted to describe the hyperglycemia-induced oxidative stress. One mechanism is the increased production $\mathrm{O}_{2}^{--}$by the disrupted ETC, which is increased according to diabetic complication state. Also, the oxidative stress is increased in diabetes because of the accelerated polyol/sorbitol pathway and the decrease in NADPH availability and thereby GSH depletion (24-26).

\subsection{Oxidative stress}

Although, free radicals have been shown to play beneficial roles in biology, especially when present in physiological concentrations, may act as a second messenger in some of the signal transduction pathways. When the production of these free radicals is greater than the ability of the cell to detoxify, an oxidative stress is developed and oxidative damage of many biological molecules, especially proteins and nucleic acids occurs $(27,28)$. The levels of $\mathrm{G}-\mathrm{SH}$, is decreased, while the lipid peroxides (LPO) and advanced glycation end product (AGE) are accumulated (28-30). 
Table 1: Different reactive species

\begin{tabular}{|c|c|c|c|}
\hline Reactivity / Remarks & $\begin{array}{l}\text { Half life } \\
(\text { in sec) }\end{array}$ & Symbol & Reactive species \\
\hline \multirow{3}{*}{$\begin{array}{l}\text { I. Reactive oxygen species } \\
\text { Generated in mitochondria, in cardiovascular system } \\
\text { and others, very highly reactive, generated during iron } \\
\text { overload and such conditions in our body }\end{array}$} & & & \multirow{3}{*}{$\begin{array}{l}\text { - Superoxide } \\
\text { - Hydroxyl Radical }\end{array}$} \\
\hline & $10^{-4} \mathrm{~s}$ & $\mathrm{O}_{2}{ }^{--}$ & \\
\hline & $10^{-9} \mathrm{~s}$ & $\cdot \mathrm{OH}$ & \\
\hline $\begin{array}{l}\text { Formed in our body by large number of reactions and } \\
\text { yields potent species like }{ }^{+} \mathrm{OH}\end{array}$ & Stable & $\mathrm{H}_{2} \mathrm{O}_{2}$ & - Hydrogen Peroxide \\
\hline $\begin{array}{l}\text { Reactive and formed from lipids, proteins, DNA, sug- } \\
\text { ars etc. }\end{array}$ & $\mathrm{S}$ & ROO* & - Peroxyl radical \\
\hline During oxidative damage & & & \\
\hline $\begin{array}{l}\text { Reacts with transient metal ions to yield reactive spe- } \\
\text { cies }\end{array}$ & Stable & $\mathrm{ROOH}$ & - Organic hydroperoxide \\
\hline $\begin{array}{l}\text { Highly reactive, formed during photosensitization } \\
\text { and chemical reactions }\end{array}$ & $10^{-6} \mathrm{~S}$ & ${ }^{1} \mathrm{O}_{2}$ & - Singlet oxygen \\
\hline $\begin{array}{l}\text { Present as an atmospheric pollutant, can react with } \\
\text { various molecules, yielding }{ }^{1} \mathrm{O}_{2} \\
\text { II. Reactive nitrogen species }\end{array}$ & $\mathrm{S}$ & $\mathrm{O}_{3}$ & - Ozone \\
\hline $\begin{array}{l}\text { Neurotransmitter and blood pressure regulator, can } \\
\text { yield potent oxidants during pathological states }\end{array}$ & $\mathrm{S}$ & NO* & - Nitric oxide \\
\hline Formed from $\mathrm{NO}_{2}$ and & $10^{-3} \mathrm{~s}$ & $\mathrm{ONOO}^{-}$ & - Peroxynitrite \\
\hline
\end{tabular}

The induction of OP and/or ON by the accumulated free radicals can be explained by several axes. An important axis occurs by inhibition the differentiation of two vital cell lines, the marrow stromal M2-10B4 cell line, and the pre-osteoblastic cell line. In this mechanism, the early differentiation marker, alkaline phosphatase (ALP) was found to be markedly increased and the mineralization in these cell lines is lowered (31). Another one, is the foundation that metallothionein (MT) has a protective effect against $\mathrm{H}_{2} \mathrm{O}_{2}$-induced inhibition of the differentiation of osteoblasts and has the ability to scavenge $\mathrm{OH} \& \mathrm{O}_{2}{ }^{--}$free radicals by mechanisms similar to $\mathrm{G}-\mathrm{SH}$ and superoxide dismutase, respectively (32-34).

It has been reported that the free radicals is a strong emitter of the expression of many cytokines and many of these cytokines are involved in bone osteoporosis including TNF$\alpha, N F-\kappa B$, IL6 and IL-1 (35). The production of these signals is regulated by steroids. While TNF- $\alpha$ and IL-1 are a powerful bone resorption effectors by increasing the number of osteoclasts, IL-6 is an osteotropic $(36,37)$. NF$\kappa \mathrm{B}$ is involved in the regulation of cell growth, differentiation, death and development of bone and is a downregulator of the differentiation of osteoblasts (38-40).

\subsection{Role of antioxidants in osteoporosis}

Oxidative stress arise when the production of the radicals oxygen and non-oxygen free radicals exceed the capacity of the antioxidants to overcome. A proper antioxidant (enzymes and non-enzymes) is essential to protect against free radicals $(41,42)$. Enzyme antioxidants include: superoxide dismutases, glutathione peroxidases, catalase, glutathione Stransferase, glutathione reductase, peroxiredoxins, glutaredoxin and thioredoxin Nonenzyme antioxidants include: Reduced glutathione (G-SH), tocopherols and $\beta$-carotenes (43).

\section{Targets of antioxidants}

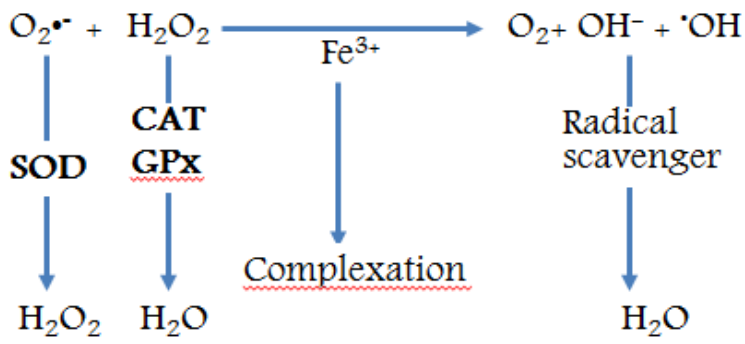

Figure 2: Possible mechanisms of antioxidants adapted from (44) 
In the post-menopause, the bone mineral density is decreased, the susceptibility for OP is increased and the antioxidants are depleted. Such condition can be alleviated by regular intake of exogenous antioxidant (45). The metabolism of calcium is dramatically affected, because of a decrease in the gastrointestinal calcium absorption and increase in the renal calcium loss. These manifestations are recorded in glucocorticoid administration. It was reported that co-administration of the antioxidants tocopherol or ascorbate can withstand the development of corticosteroid-induced ON (46-48). In addition, a secondary hyperparathyroidism has been suggested as a determinant effector of bone (49).

\section{Osteoporotic biomarkers}

It have been suggested that osteoporosis is associated with several biochemical markers that can be taken as a monitor for the oxidative stress-induced $\mathrm{OP}$ and $\mathrm{ON}$ to follow-up and the possible ameliorative effect of a natural antioxidant.

\section{Antioxidants}

\subsection{Genistein (Giensing or Ginseng)}

Ginseng, one of the most popular oriental medicinal herbs, widely used as an herbal remedy for various physiological and pathological disorders. White and red ginseng have been used as an excellent stimulant for the immune and antimicrobial defenses (51). Genistein is not only an effective scavenger of free radicals in vitro, but also a strong inhibitor of cell-derived $\mathrm{H}_{2} \mathrm{O}_{2}$ formation in vivo. It has an antioxidant capacity that may exceed that of acrobate and tocopherols (52).

\subsection{Ginseng as a hypoglycemic effector}

An proposed and accepted anti-osteoporetic effect of ginseng is the hypoglycemic effect. It has been reported that the blood glucose level and the glycogen content are improved and controlled in ginseng-supplemented diabetics. One possible mechanism of this hypoglycemic effect of ginseng is the antioxidant scavenging effect, enhancement of the aerobic glycolysis through stimulation of $\beta$-adrenoreceptor and increase of various rate-limiting TCA enzyme activities (53). Ginseng supplementation significantly reduce the incidence of $\mathrm{ON}$ in the most studied corticosteroid- induced ON animal models, characterized by a marked increase in the GSH content and MDA levels decreased. Thus providing a fact that oxidative stress and ON was inhibited by ginseng (16, 28).

\section{Involvement of oxidative stress in bone pathophysiology}

The pathophysiology of the oxidative stress varies according to the load of the stress and the provided antioxidant capacity. Oxidative stress in low levels may function as a signal mediator for cell growth and cellular signaling (54). In contrast, higher oxidative stress is harmful, causing cellular injury and involved in various disease pathogenesis. The damage include enzymes, structural proteins, lipids, and DNA are seriously affected in a way can lead to apoptosis (55). Bone architecture and osteoblast / osteoclast balance is also altered (28).

\section{Apoptosis}

The programmed cell death (PCD), apoptosis, is actually essential for the normal development and homeostasis and the removal of the damaged, infected and potentially neoplastic cells (56). Glucocorticoids are potent inducers of apoptosis in many cells(30). GCs have proapoptotic effects on osteoblasts and osteocytes due to activation of caspase-3, the key mediator of apoptosis (56). As previously mentioned, apoptosis-induced by intake of corticosteroids varies according to the form of the receptor present; glucocorticoid receptors $\alpha-\mathrm{C}(\mathrm{GR} \alpha-\mathrm{C})$ is a potent apoptotic inducer than GR $\alpha$, while GR $\alpha-D$ is less (57).

\subsection{Caspases}

Caspases are major player in the cell death by apoptosis. These cysteine-dependent caspases are affected by many factors especially the redox state of the cell. As shown in figure (3): The function of glucocorticoid receptors can propagate signals either for pro-apoptotic genes or for anti-apoptotic genes that can either lead to apoptosis or cell survival, respectively depending on the cell type or tissue (58, 59). 
Table 2: Biomarkers can be used to follow-up the oxidative stress-induced osteoporosis, adapted from (50).

Biomarkers

1. Markers of -ALP: An osteoblastic differentiation marker.

bone formation $\quad$-Serum measurement of total and bone-specific alkaline phosphatase (BALP)

- Osteocalcin (OC),

-Type I collagen extension peptides.

2. Assessment of bone resorption

- Urine specimens were assayed for markers of bone resorption: $\mathrm{N}$ - telopeptides (NTX), free pyridinolines (Pyr), free deoxypyridinoline.

- Measurement of fasting urinary calcium and hydroxyproline,

-Urinary hydroxylysine glycosides, urinary excretion of the pyridinium cross-link and bone - specific alkaline phosphatase.

- Osteoclast enzymes: .Tartarate-resistant acid phosphatase (TRACP) andCathepsin K.

3. Biochemical determinations

-The lipid peroxide marker, MDA.

-Calcitonin.

-DNA damage marker, 8-OHdG.

-Antioxidant status: Reduced blood glutathione (G-SH).

-The antioxidant enzymes: SOD, Catalase and Glutathione peroxidase (GPX).

-Endothelin (ET) in plasma.

-PTH, Calcium \& Phosphorus.

4. Immunohisto- -The presence/absence of advanced glycation end-product expression.

chemical investiga- -Proinflammatory cytokines: (IL-1 $\alpha, 1 \beta, 6, \mathrm{TNF}-\alpha$ ).

tions

-Anti-inflammatory: (IL-4, 10).

-Bone-marrow-specific cytokines: (IL-7 \& 11).

-Caspase: $1,3,7 \& 9$.

-Caspase-activated DNase (CAD).

-Adipogenic transcription factor (PPAR $\gamma$ ).

-TGF- $\beta 2$.

- Vascular endothelial growth factor (VEGF).

- Tumor necrosis factor- $\alpha$ (TNF- $\alpha$ ).

- Tumor necrosis factor-receptor-1 (TNF-R1).

-The pro-apoptotic Bcl-2 (Bim).

-The pro-apoptotic proteins (Bax/Bak).

- NF-кB: For osteoblastic differentiation of BMSCs.

5. Determination the gene expression
-Sphingomyelin Synthase-2.

-PTH receptor-1.

Table 3: The protective role of different antioxidants in osteoporosis, adapted from (44).

\begin{tabular}{|c|c|}
\hline Antioxidant & Effect \\
\hline $\begin{array}{l}\text { Reduced glu- } \\
\text { tathione } \\
\text { (G-SH) }\end{array}$ & $\begin{array}{l}\text { Reduced glutathione is important for the maintenance of the cytoskeleton, stabi- } \\
\text { lizes the lysosomal membrane and suppresses injury to the vascular endothelium } \\
\text { and wall by inhibiting an increase of lipoperoxides. }\end{array}$ \\
\hline Vitamin E & $\begin{array}{l}\text { Vitamin E deficiency impairs calcium transport via the intestine and reduces bone den- } \\
\text { sity, free radical scavenger and has been shown to offer protection against free } \\
\text { radical-associated diseases, such as atherosclerosis, cancer and osteoporosis. }\end{array}$ \\
\hline Vitamin C & $\begin{array}{l}\text { Enhances collagenogenesis, possible effect on bone formation, the antioxidant effect } \\
\text { on osteoporosis is under investigation }\end{array}$ \\
\hline Vitamin A & $\begin{array}{l}\text { Excess vitamin A intake has been associated with accelerated bone loss, but this re- } \\
\text { quires further investigation. }\end{array}$ \\
\hline Genistein & Free radicals scavenger, inhibitor of cell-derived $\mathrm{H}_{2} \mathrm{O}_{2}$ formation. \\
\hline Ginkgo biloba & Free radical scavenger. \\
\hline
\end{tabular}


Intrinsic as well as extrinsic apoptotic pathways are suggested as possible mechanisms of GC-induced apoptosis. The activation of the intrinsic apoptotic pathway is the classic mechanism (60). Mitochondrial-dependent or mitochondrial-independent mechanisms are involved in the extrinsic apoptotic pathway. Glucocorticoid signaling increases the expression of the pro-apoptotic Bcl-2 family member Bim, which can activate the pro-apoptotic proteins Bax/Bak to disrupt mitochondrial membrane potential, resulting in the release of cytochrome $\mathrm{c}$ and other apoptogenic proteins. This leads to caspase 9 activation and subsequent effector caspase 3 activation and apoptosis occurs. Other factors that may influence the intrinsic pathway during GC-induced apoptosis include up-regulation of other proapoptotic proteins such as Bad and Puma, or down regulation of anti-apoptotic proteins such as Bcl-2 or Bcl-xL. A major checkpoint in this pathway is the ratio between proapoptotic (Bax) to anti-apoptotic (Bcl-2) members, which is something unique for apoptosis. Caspase- 3 and caspase- 7 cleave this ICAD, resulting in the release of active CAD (61).

\subsection{Steroid-induced OP- animal models}

Several animal models are proposed to describe the pathogenesis of corticosteroidinduced $\mathrm{ON}$ and OP, differing according to the animal used (rabbits or mice or rats), the steroid drug, the dose used either acute or chronic doses and the period of the experiment (38).

Natural antioxidants could be applied as a functional material to prevent diseases caused by oxidative stress. The ginseng can significantly decrease the incidence of osteoporosis and osteonecrosis in the steroid-treated animal models e.g. rabbit. The oxidative stress is inhibited and the vascular endothelial dysfunction is ameliorated. The precise mechanism still requires a further in vivo study.

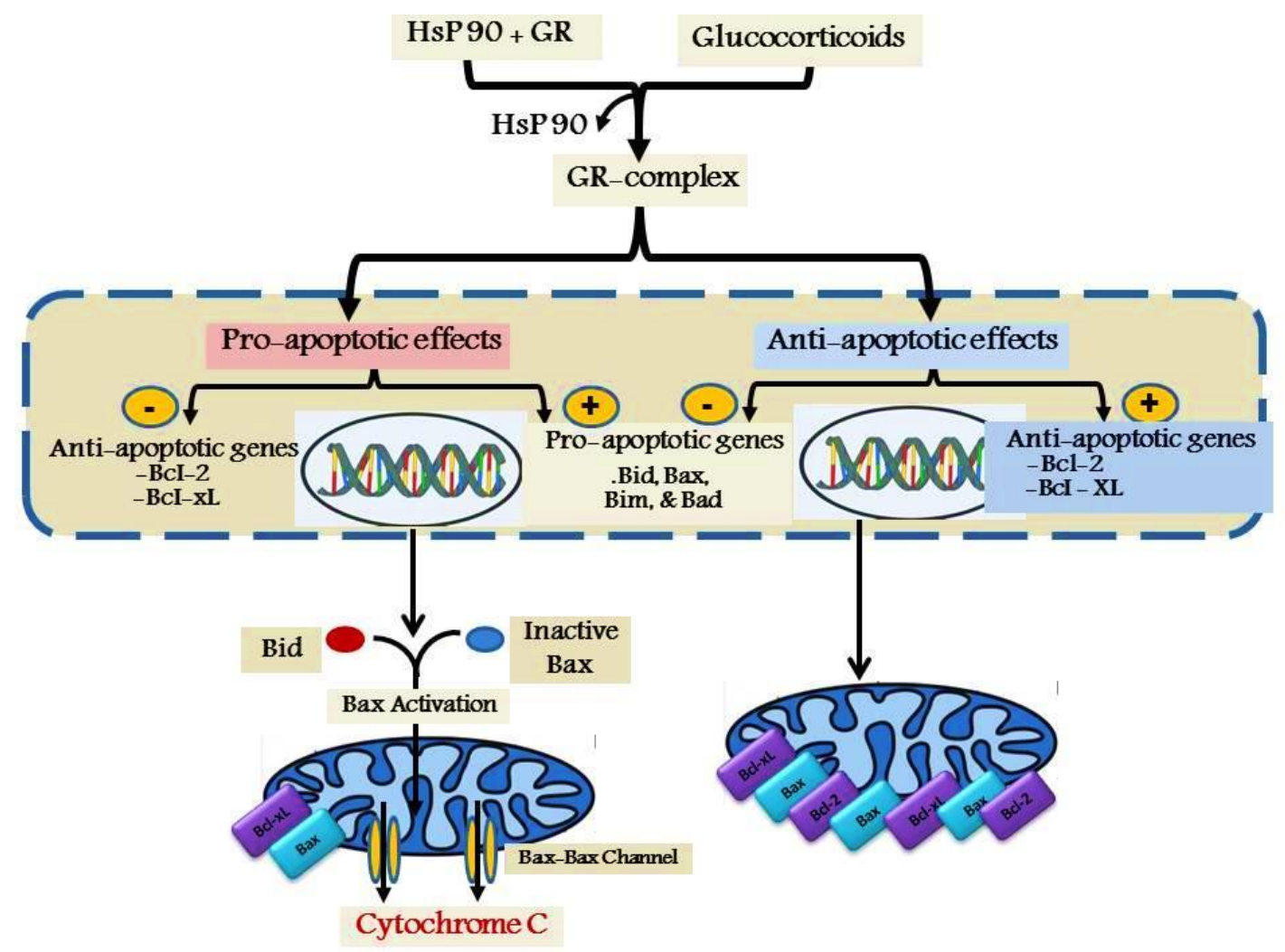

Figure 3: Glucocorticoid signaling through GR, adapted after (29) 


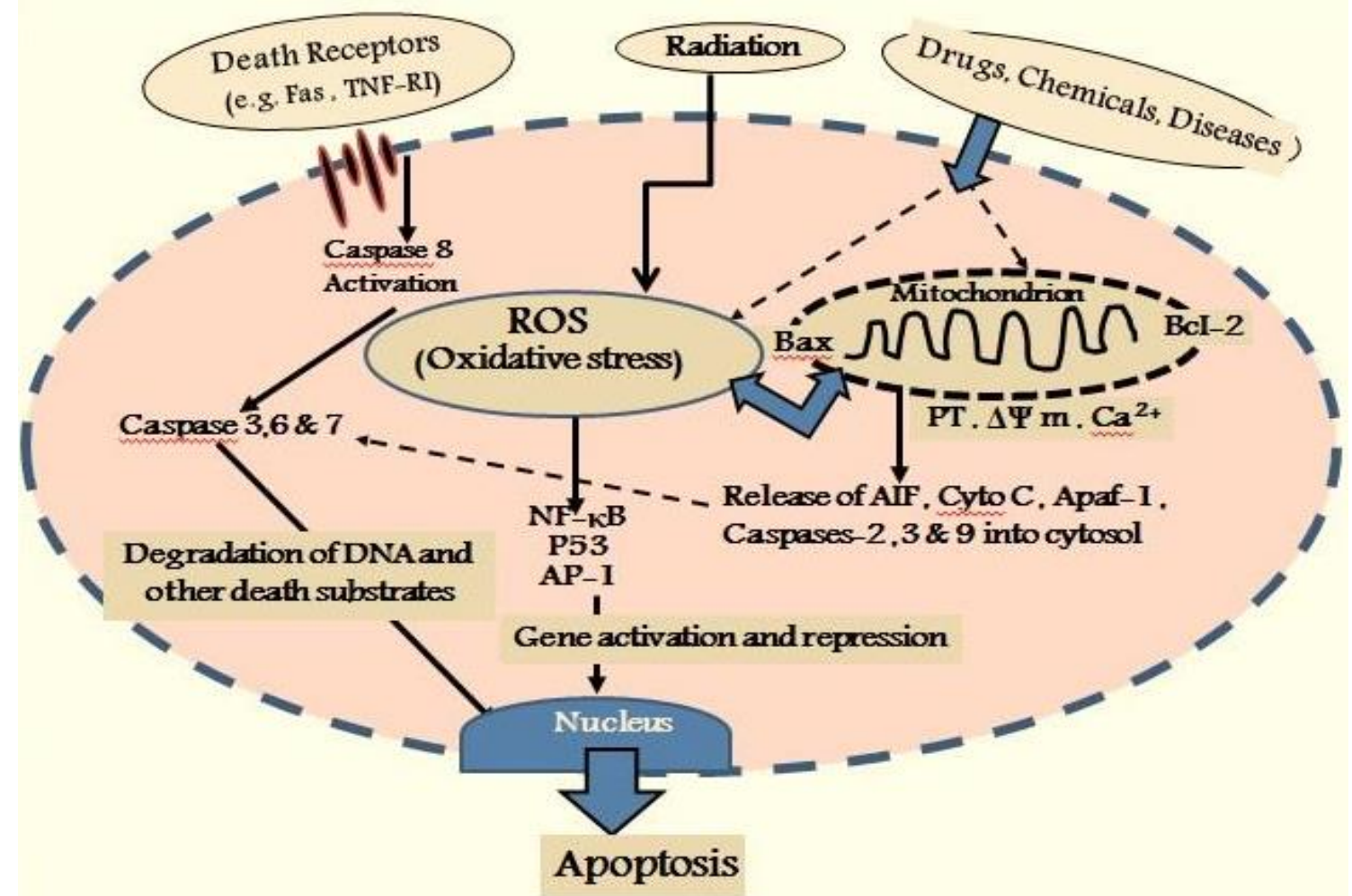

Figure 4: Schematic model of mammalian cell death pathway, adapted from (56)

Table 4: Experimental animal models for steroid-induced OP

\begin{tabular}{|c|c|c|c|c|}
\hline Animal & Drug & Dose & Exp. Period & Biomarkers \\
\hline $\begin{array}{l}\text { Male NewZea- } \\
\text { land white rabbits }\end{array}$ & Methylprednisolone & $\begin{array}{l}4 \mathrm{mg} / \mathrm{kg} \\
\text { B.Wt. }\end{array}$ & 14 days ref ${ }^{(36)}$ & GSH and LPO \\
\hline $\begin{array}{l}\text { Female Japanese } \\
\text { white rabbits }\end{array}$ & Methylprednisolone & $\begin{array}{l}4 \mathrm{mg} / \mathrm{kg} \text {, } \\
\text { I.M. once }\end{array}$ & $\begin{array}{l}\text { Sampling at days: } \\
3^{\text {rd }}, 5^{\text {th }} \& 14^{\text {th }}, \text { Ref } \\
\text { (36) }\end{array}$ & $\begin{array}{l}\text { Histopathology, Bio- } \\
\text { chemical and immuno- } \\
\text { histothemisty }\end{array}$ \\
\hline $\begin{array}{l}\text { Female Japanese } \\
\text { white rabbits }\end{array}$ & Methylprednisolone & $\begin{array}{l}40 \\
\mathrm{mg} / \mathrm{kg}, \\
\text { I.M. once }\end{array}$ & $\begin{array}{l}\text { Sampling at days: } \\
1^{\text {st }}, 3^{\text {rd }}, 5^{\text {th }} \& 14^{\text {th }} \\
\operatorname{Ref}^{(18)}\end{array}$ & $\begin{array}{l}\text { Histopathology, Bio- } \\
\text { chemical and immuno- } \\
\text { histothemisty }\end{array}$ \\
\hline $\begin{array}{l}\text { Male Japanese } \\
\text { white rabbits }\end{array}$ & $\begin{array}{l}\text { Methylprednisolone } \\
\text { acetate }\end{array}$ & $\begin{array}{l}20 \\
\mathrm{mg} / \mathrm{kg} \text {, } \\
\text { I.M. once }\end{array}$ & $\begin{array}{l}-2-10 \text { weeks , Ref } \\
(62)\end{array}$ & $\begin{array}{l}\text { Histopathology, hemato- } \\
\text { logical and immunohis- } \\
\text { tothemisty }\end{array}$ \\
\hline $\begin{array}{l}\text { Male adult } \\
\text { Newzealand } \\
\text { white rabbits }\end{array}$ & Methylprednisolone & $\begin{array}{l}20 \\
\mathrm{mg} / \mathrm{kg} \text {, } \\
\text { I.M. once }\end{array}$ & $\begin{array}{l}\text { Sampling at days: } \\
3^{\text {rd }}, 5^{\text {th }}, 7^{\text {th }} \& 14^{\text {th }} \\
\text {, } \operatorname{Ref}^{(63) .}\end{array}$ & $\begin{array}{l}\text { Histopathology, Bio- } \\
\text { chemical and immuno- } \\
\text { histothemisty }\end{array}$ \\
\hline Rats & $\begin{array}{l}\text { Slow-release Pred- } \\
\text { nisone pellets, S.C. } \\
\text { implanted }\end{array}$ & $\begin{array}{l}1.5 \mathrm{mg} / \\
\mathrm{Kg} \mathrm{B} . \\
\text { Wt. }\end{array}$ & 6 months $\operatorname{Ref}^{(60)}$ & $\begin{array}{l}\text { Histopathology, Bio- } \\
\text { chemical and immuno- } \\
\text { histothemisty }\end{array}$ \\
\hline
\end{tabular}

\section{Conclusion}

Finally, we can conclude that, the causes of osteonecrosis and osteoporosis are multifactorial. Both in vitro and in vivo data have recently shown that steroid-associated oxidative in- jury exerts a crucial role in the development of $\mathrm{OP}$ and ON. Several antioxidants have been reported to effectively suppress the development of this illness. Soon after steroid administration, attenuation of the protective antioxidative capability occurs, leading to tissue and 
protein modifications, especially in bone tissues, vascular endothelial dysfunction, which contributes to local intravascular thrombosis and circulatory disturbances, concomitantly with the development of osteoporesis. It is of a great clinical significance if natural products without side effects on the human body were able to indirectly increase the intravital antioxidant defense system and directly eliminate excessive ROS.

\section{Conflict of interest}

None of the authors have any conflict of interest to declare.

\section{References}

1. Rao, L., Will tomatoes prevent osteoporosis. Endocrinology Rounds, 2005; 5: 118-35.

2. Bouvard, B., et al., Ultrastructural characteristics of glucocorticoid-induced osteoporosis. Osteoporosis international, 2009; 20: 1089--92.

3. Boyle, W.J., W.S. Simonet, and D.L. Lacey, Osteoclast differentiation and activation. Nature, 2003; 423: 337.

4. Jilka, R.L., et al., Increased bone formation by prevention of osteoblast apoptosis with parathyroid hormone. The Journal of clinical investigation, 1999; 104: 439-46.

5. Cole, T.J., et al., Targeted disruption of the glucocorticoid receptor gene blocks adrenergic chromaffin cell development and severely retards lung maturation. Genes \& development, 1995; 9: $1608-21$.

6. Schmidt, S., et al., Glucocorticoid-induced apoptosis and glucocorticoid resistance: molecular mechanisms and clinical relevance. Cell death and differentiation, 2004; 11: S45.

7. O'brien, C.A., et al., Glucocorticoids act directly on osteoblasts and osteocytes to induce their apoptosis and reduce bone formation and strength. Endocrinology, 2004; 145: 1835-41.

8. Moudgil, V., Steroid receptors in health and disease An Oakland University-Serono Symposia, USA Conference, September 20-23, 1987, Meadow Brook Hall, Rochester. MI 48309-9908, USA. FEBS letters, 1988; 226: 213-6.

9. Jondal, M., A. Pazirandeh, and S. Okret, A role for glucocorticoids in the thymus? TRENDS in Immunology, 2001; 22: 185-6.

10. Laudet, V. and H. Gronemeyer, The nuclear receptor factsbook. 2002: Gulf Professional Publishing.

11. Bai, X.-c., et al., Oxidative stress inhibits osteoblastic differentiation of bone cells by ERK and NF- $\mathrm{KB}$. Biochemical and biophysical research communications, 2004; 314: 197-7.

12. Briot, K., et al., 2014 update of recommendations on the prevention and treatment of glucocorticoid-induced osteoporosis. Joint Bone Spine, 2014; 81: 493-1.

13. Nishimura, J. and S. Ikuyama, Glucocorticoid-induced osteoporosis: pathogenesis and management. Journal of bone and mineral metabolism, 2000; 18: 350-2.

14. Provvedini, D.M., et al., 1, 25dihydroxyvitamin D3 receptors in human leukocytes. Science, 1983; 221: 1181-3.

15. Tsoukas, C.D., D.M. Provvedini, and S.C. Manolagas, 1, 25-dihydroxyvitamin D3: a novel immunoregulatory hormone. Science, 1984; 224: 1438-40.

16. Manolagas, S.C., Steroids and osteoporosis: the quest for mechanisms. The Journal of clinical investigation, 2013; 123: 1919-21.

17. Yang, S.Y., et al., Antioxidant and AntiOsteoporosis Activities of Chemical Constituents of the Stems of Zanthoxylum piperitum. Molecules, 2018; 23: 457.

18. Ichiseki, T., et al., The initial phase of oxidative stress in a steroid-induced osteonecrosis rabbit model. Advances in Bioscience and Biotechnology, 2012; 3: 978.

19. Okazaki, S., et al., Oxidative Stress In The Corticosteroid-induced Osteonecrosis Of The Femoral Head Rat Model.

20. Roux, C., Osteoporosis in inflammatory joint diseases. Osteoporosis International, 2011; 22: 421-33.

21. Halliwell, B. and J.M. Gutteridge, Free radicals in biology and medicine. 2015: Oxford University Press, USA.

22. Valko, M., et al., Free radicals and antioxidants in normal physiological functions and human disease. The international journal of biochemistry \& cell biology, 2007; 39: 44-84.

23. Orrenius, S., V. Gogvadze, and B. Zhivotovsky, Mitochondrial oxidative stress: implications for cell death. Annu. Rev. Pharmacol. Toxicol., 2007; 47: 143-83.

24. Farrugia, G. and R. Balzan, Oxidative stress and programmed cell death in yeast. Frontiers in oncology, 2012; 2: 64.

25. Matés, J.M., et al., Oxidative stress in apoptosis and cancer: an update. Archives of toxicology, 2012; 86: 1649-65.

26. Das, J., et al., Mangiferin exerts hepatoprotective activity against D-galactosamine in- 
duced acute toxicity and oxidative/nitrosative stress via Nrf2-NFkB pathways. Toxicology and applied pharmacology, 2012; 260: 35-7.

27. Valko, M., H. Morris, and M. Cronin, Metals, toxicity and oxidative stress. Current medicinal chemistry, 2005; 12: 1161-1208.

28. Abdollahi, M., et al., Pesticides and oxidative stress: a review. Medical Science Monitor, 2004; 10: RA141-7.

29. Gruver-Yates, A.L. and J.A. Cidlowski, Tissue-specific actions of glucocorticoids on apoptosis: a double-edged sword. Cells, 2013; 2: 20223.

30. Anderson, K., et al., Free radicals and reactive oxygen species in programmed cell death. Medical hypotheses, 1999; 52: 451-63.

31. Andreyev, A.Y., Y.E. Kushnareva, and A. Starkov, Mitochondrial metabolism of reactive oxygen species. Biochemistry (Moscow), 2005; 70: 200-14.

32. Pratt, W.B. and D.O. Toft, Steroid receptor interactions with heat shock protein and immunophilin chaperones. Endocrine reviews, 1997; 18: 306-60.

33. Oakley, R.H., M. Sar, and J.A. Cidlowski, The human glucocorticoid receptor isoform expression, biochemical properties, and putative function. Journal of Biological Chemistry, 1996; 271: 9550-9.

34. Finkel, T. and N.J. Holbrook, Oxidants, oxidative stress and the biology of ageing. Nature, 2000; 408: 239.

35. Li, G.-Y., et al., Edaravone, a novel free radical scavenger, prevents steroid-induced osteonecrosis in rabbits. Rheumatology, 2012; 52: 438-47.

36. Ichiseki, T., et al., Oxidative stress and vascular permeability in steroid-induced osteonecrosis model. Journal of Orthopaedic Science, 2004; 9: 509-15.

37. Mody, N., et al., Oxidative stress modulates osteoblastic differentiation of vascular and bone cells. Free Radical Biology and Medicine, 2001; 31: 509-19.

38. Key Jr, L., et al., Oxygen derived free radicals in osteoclasts: the specificity and location of the nitroblue tetrazolium reaction. Bone, 1990; 11: $115-9$.

39. Steinbeck, M.J., et al., NADPH-oxidase expression and in situ production of superoxide by osteoclasts actively resorbing bone. The Journal of Cell Biology, 1994; 126: 765-772.

40. Suda, N., et al., Participation of oxidative stress in the process of osteoclast differentiation.
Biochimica et Biophysica Acta (BBA)-General Subjects, 1993; 1157: 318-23.

41. Basu, S., et al., Association between oxidative stress and bone mineral density. Biochemical and biophysical research communications, 2001; 288: 275-9.

42. Lee, Y.-S., X. Chen, and J.J. Anderson, Physiological concentrations of genistein stimulate the proliferation and protect against free radicalinduced oxidative damage of MC3T3-E1 osteoblast-like cells. Nutrition Research, 2001; 21: 1287-98.

43. Baker, P.J., The role of immune responses in bone loss during periodontal disease. Microbes and Infection, 2000; 2: 1181-92.

44. Abdollahi, M., et al., Role of oxidative stress in osteoporosis. Therapy, 2005; 2: 787-96.

45. Garnero, P., et al., Markers of bone turnover predict postmenopausal forearm bone loss over 4 years: the OFELY study. Journal of Bone and Mineral Research, 1999; 14: 1614-21.

46. Iotsova, V., et al., Osteopetrosis in mice

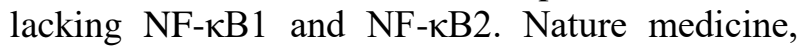
1997; 3: 1285.

47. Deyama, Y., et al., Inactivation of NF- $\kappa B$ involved in osteoblast development through interleukin-6. Biochemical and biophysical research communications, 2001; 282: 1080-4.

48. Kurokouchi, K., et al., TNF- $\alpha$ increases expression of IL-6 and ICAM-1 genes through activation of NF- $\kappa \mathrm{B}$ in osteoblast-like ROS17/2.8 cells. Journal of Bone and Mineral Research, 1998; 13: $1290-9$.

49. Polidori, M.C., et al., Profiles of antioxidants in human plasma. Free Radical Biology and Medicine, 2001; 30: 456-62.

50. Meier, C., et al., Supplementation With Oral Vitamin D3 and Calcium During Winter Prevents Seasonal Bone Loss: A Randomized Controlled Open-Label Prospective Trial. Journal of Bone and Mineral Research, 2004; 19: 1221-30.

51. Ricci, C., et al., Mitochondrial DNA damage triggers mitochondrial-superoxide generation and apoptosis. American Journal of PhysiologyCell Physiology, 2008; 294: C413-22.

52. Mikami, T., et al., Prevention of steroidinduced osteonecrosis by intravenous administration of vitamin $\mathrm{E}$ in a rabbit model. J Orthop Sci, 2010; 15: 674-7.

53. Martindale, J.L. and N.J. Holbrook, Cellular response to oxidative stress: signaling for suicide and survival. J Cell Physiol, 2002; 192: 1-15.

54. Zhou, J.-Y., et al., Corticosterone exerts immunostimulatory effects on macrophages via en- 
doplasmic reticulum stress. BJS, 2010; 97: 281-93.

55. Colavitti, R., et al., Reactive oxygen species as downstream mediators of angiogenic signaling by vascular endothelial growth factor receptor-2/KDR. J Biol Chem, 2002; 277: 3101-8.

56. Kannan, K. and S.K. Jain, Oxidative stress and apoptosis. Pathophysiology, 2000; 7: 153-63.

57. Angeli, A., et al., High prevalence of asymptomatic vertebral fractures in postmenopausal women receiving chronic glucocorticoid therapy: a cross-sectional outpatient study. Bone, 2006; 39: 253-9.

58. Salvesen, G.S. and V.M. Dixit, Caspase activation: the induced-proximity model. Proc Natl Acad Sci U S A, 1999; 96: 10964-7.

59. Cao, Y., et al., Glucocorticoid receptor translational isoforms underlie maturational stagespecific glucocorticoid sensitivities of dendritic cells in mice and humans. Blood, 2013: blood-
2012-05-432336.

60. Kerachian, M.A., et al., New insights into the pathogenesis of glucocorticoid-induced avascular necrosis: microarray analysis of gene expression in a rat model. Arthritis Research \& Therapy, 2010; 12: R124.

61. Sinha, K., et al., Oxidative stress: the mitochondria-dependent and mitochondriaindependent pathways of apoptosis. Arch Toxicol, 2013; 87: 1157-80.

62. Yamamoto, T., et al., Effects of pulse methylprednisolone on bone and marrow tissues. Corticosteroid-induced osteonecrosis in rabbits. Arthritis \& Rheumatism: Official Journal of the American College of Rheumatology, 1997; 40: 2055-64.

63. Lu, B.-B. and K.-H. Li, Lipoic acid prevents steroid-induced osteonecrosis in rabbits. Rheumatology international, 2012; 32: 1679-83. 